\title{
STRATEGI PENGEMBANGAN PELAYARAN PERINTIS DENGAN ANALISA SWOT MENUJU PENGUATAN PROGRAM TOL LAUT DAN INDONESIA SEBAGAI POROS MARITIM
}

\author{
Willem Thobias Fofid
}

Asisten Dosen PIP Semarang

\begin{abstract}
ABSTRAK
Penelitian ini bertujuan untuk menganalisis strategi kebijakan yang dapat diimplementasikan untuk pengembangan pelayaran perintis Dermaga APO di pelabuhan Jayapura adalam rangka meningkatkan kinerja pelabuhan menuju penguatan program tol laut. Dermaga Apo sebagai pelayaran perintis pelabuhan Jayapura memiliki kelemahankelemahan yang telah diidentifikasi secara observasi dan studi data primer. Kelemahankelemahan Pelayaran Perintis ini berakibat pada disparitas harga untuk provinsi Papua sebagaimana fungsi pelabuhan sebagai fungsi logistik. Berdasarkan hasil analisis SWOT disimpulkan bahwa kinerja Dermaga Apo sebagai Pelayaran Perintis Pelabuhan Jayapura berada pada kuadan I dengan posisi $(0,83 ; 1,44)$. Strategi yang digunakan Pelayaran Perintis pelabuhan Jayapura guna mengembangkan pelayaran perintis agar lebih efisien sesuai fungsinya adalah adalah strategi SO (strength-opportunity). Strategi SO tersebut yaitu penguatan fungsi pelayaran perintis sebagai pendukung pengembanagn pusat kegiatan ekonomi dan pendukung pemerintah dalam MP3EI, pengembangan sarana dan prasarana pelabuhan perintis agar dapat menunjang segala aktivitas dan efisiensi pelabuhan, pengembangan wilayah hinterland untuk memaksimalkan fungsi pelayaran perintis yang sibuk dan padat.
\end{abstract}

\section{Keywords : pelayaran perintis, dermaga APO, SWOT analysis}

\section{PENDAHULUAN}

Indonesia sebagai negara dengan status Achipelago Island atau negara kepulauan terbesar di dunia yang memiliki batas wilayah perairan yang sangat luas (lebih dari $67 \%$ adalah perairan) yang eksitensinya telah diakui berdasarkan ketentuan Konvensi Hukum Laut UNCLOS 1982 (United Nations Convention on the Law of the Sea, 1982), yang bahkan diteliti ternyata luas laut keseluruhan Negara Kesatuan Republik Indonesia adalah 6.315.222 $\mathrm{Km}^{2}$ (Luas Laut seluruh dunia: 361 juta $\mathrm{km}^{2}$ ), terdiri dari luas wilayah laut teritorial $282.583 \mathrm{Km}^{2}$ (80\% perairan) dan darat 20\%, dengan luas laut nasional/perairan wilayah pedalaman dan kepulauan 3.092.085 $\mathrm{Km}^{2}$, dengan Zona Ekonomi Eksklusif / ZEE seluas 2.936.345 $\mathrm{km}^{2}$, panjang garis pantai kepulauan
Indonesia $99.093 \mathrm{Km}^{2}$, serta memiliki lebih dari 17.504 pulau yang membentang di antara pulau-pulau besar seperti Pulau Sumatera, Jawa, Kalimantan, Sulawesi, Nusa Tenggara, Maluku dan Papua. Sebagai negara Kepulauan tentu sangat dibutuhkan sebuah sistem pelayaran yang terintegrasi dan proposional untuk dapat memenuhi kebutuhan perekonomian dan kewilayahan nasional. Sebagai anggota resmi Internasional Maritime Organization yang dikenal dengan $I M O$ sejak tanggal 18 Januari 1961, Indonesia harus meratifikasi dan mengimplementasikan aturan internasional yang diturunkan lewat regulasi perundangan-undangan nasional. Salah satunya Konvensi mengenai keselamatan yaitu adanya Convention SOLAS (Safety of Lifwe At Sea) yang mana menuntut setiap pelabuhan dalam melayani kapal-kapal niaga harus memberlakukan 
penerapannya dalam pelayanan bagi kapalkapal yang sandar yang akan melakukan arus bongkar muat muatan barang dan manusia. Sehingga sudah saatnya pelabuhan harus dibangun dan dirancang guna melayani kapal dengan melihat kebutuhan-kebutuhan suatu daerah sesuai dengan jenis kapal yang akan sandar dan masuk untuk melayani arus bongkar muat muatan. Salah satu daerah yang menjadi fokus untuk pengembangan pelabuhan Indonesia yaitu daerah T3P (Terpencil, Terluar, Tertinggal dan Perbatasan) dalam menunjang konektivitas, sebagai contoh pengembangan system pelayaran khusus di daerah T3P (Terpencil, Terluar, Tertinggal dan Perbatasan) yaitu pelayaran perintis dan perencanaan pengembangan pelabuhan di Jayapura, Provinsi Papua, yang merupakan daerah ujung timur Indonesia.

Pengaruh dan dampak permasalahan tersebut bagi rakyat Indonesia di kawasan Indonesia Timur tentu tidak seberuntung saudara mereka di kawasan Indonesia Barat. Minimnya pembangunan diperburuk mahalnya harga komoditas membuat jurang pemisah perekonomian melebar. Oleh karena mahalnya komoditas salah satunya dipicu mahalnya biaya logistik. Mahalnya harga komoditas telah terkonfirmasi. Sebagai contoh kasus yang terjadi pada tahun 2013 (dimuat di harian Kompas) salah satu warga Jayapura yang ditelepon dari Jakarta Senin (18/2/2013), Harga ayam kampung di Jayapura juga Rp 200.000 per ekor. Ayam kampung merupakan salah satu makanan wajib dalam sebuah keluargan sebab disukai oleh berbagai kalangan. Di Jakarta, harga ayam kampung hanya Rp 75.000 per ekor. Tingginya harga komoditas di Papua, salah satunya dipicu ketidakmampuan Papua berswasembada, untuk memproduksi sendiri kebutuhan penduduknya. Upaya untuk mendatangkan komoditas dari pulau lain pun tidak mudah. Inefisiensi pelabuhan membuatnya sulit. Inefisiensi pelabuhan, yang dipicu rendahnya produktivitas bongkar muat di Pelabuhan Jayapura, telah memaksa kapal sandar lebih lama. Penggunaan kapal tidak maksimal pada akhirnya melambungkan tarif pelayaran. Konsumen di Jayapura, juga kawasan lain di Indonesia bagian timur, akhirnya harus membeli barangbarang dengan harga lebih mahal. Sebagai perbandingan, Pelabuhan Jayapura membongkar muat kapal ukuran 500 unit peti kemas ukuran 20 kaki (twenty-foot equivalent units/ TEUs) selama tiga hari. Terminal Peti Kemas Internasional Jakarta (JICT) di Pelabuhan Tanjung Priok, Jakarta, mampu membongkar kapal sejenis dalam 14 jam.

Rendahnya arus kunjungan kapal dan muatan di Pelabuhan Jayapura, hal ini disebabkan masih terdapatnya kapal-kapal niaga yang masuk tidak sesuai dengan jenis-jenis muatan yang tersedia sehingga kapal-kapal yang beroperasi di pelabuhan Jayapura tidak dapat memaksimalkan ruang-ruang muat yang ada, hal ini tentu berdampak pada beban operasional sebuah kapal yang tidak sebanding dengan biaya/cost dari sebuah voyage perjalanan dengan rute liners/tetap maupun tidak tetap/tramper, dengan demikian masih terdapatnya ruang muat yang kosong pada kapal-kapal yang melayani di pelabuhan Jayapura setelah bongkar muat dan akan berangkat ke pelabuhan selanjutnya dan atau bahkan sering terjadi penumpukan muatan di gudang, depo kontainer dan penyimpanan barang atau di pelabuhan.

Kebijakan Pemerintah Pusat dalam program visi dan misi Nawa Cita lewat Kementerian Perhubungan dan Pemerintah Daerah Provinsi Papua dan Kota Jayapura dalam program tol laut dan poros maritim khususnya bagi pelayaran perintis untuk dalam pengembangan kawasan pelabuhan Jayapura, diharapkan dapat memberikan dampak positif bagi perkembangan Kota Jayapura sebagai Ibu Kota Provinsi Papua dan juga terlebih khusus dapat melayani kapal-kapal niaga yang akan beroperasi pada pelayaran perintis dengan rute terpencil, terluar, tertinggal dan perbatasan dalam menunjang konektivitas. Arus 
muatan yang menjadi tolok ukur keberhasilan program tersebut diharapkan mampu menekan disparitas harga dan dapat menyetarakan harga-harga di seluruh pelosok Indonesia khsusunya di Indonesia timur. Revitalisasi pelabuhan diperlukan agar mampu memperbaiki keadaan. Dalam rangka revitalisasi pelabuhan pelayaran perintis perlu ditetapkan strategi kebijakan yang terintegrasi yaitu secara terpadu yang menghubungkan keunggulan-keunggulan guna mengatasi persoalan yang sedang dihadapi maupun ancaman yang akan datang.

Informasi-informasi internal maupun eksternal mengenai pelayaran perintis tersebut telah dimanfaatkan dan dianalisis untuk perumusan strategi dalam modelmodel kualitatif, sehingga diperoleh formulasi strategi yang dapat diberikan sebagai masukan dan bahan pertimbangan kepada pihak yang berwenang dalam rangka pengembangan pelayaran perintis. Perumusan strategi kebijakan pengembangan pelayaran perintis tersebut difokuskan dengan menggunakan modelmodel kualitatif, seperti matriks Internal Factors Analysis Summary (IFAS), matriks External Factors Analysis Summary (EFAS), dan matriks Strengths Weaknesses Opportunities Threats (SWOT). Metode pengumpulan data melalui kuesioner untuk meminta informasi yang dibutuhkan.

\section{METODE PENELITIAN}

Data pada penelitian ini diperoleh dari hasil pengumpulan data primer dan data sekunder. Data primer merupakan hasil penyebaran kuesioner kepada para pengguna jasa kepelabuhanan dan pihak stakeholder di Pelabuhan Jayapura. Pengambilan data sekunder diperoleh dari literatur-literatur. Data yang diperoleh digunakan untuk menganalisa rencana strategi pengembangan dermaga Apo sebagai pelayaran perintis.

\section{HASIL PENELITIAN DAN PEMBAHASAN}

\section{Kondisi Dermaga APO sebagai Pelayaran Perintis pada Pelabuhan Jayapura}

Dermaga APO merupakan dermaga yang diperuntukkan untuk kapal perintis. Secara legalitas dituangkan juga dalam SKB Menteri Dalam Negeri dan Menteri Perhubungan No. 194 B/KM 69 tanggal 26 Nopember 1996.

$$
\begin{array}{ll}
\text { DERMAGA APO } & : 346,5 \mathrm{~m}^{2} \\
\text { - Panjang } & : 33 \mathrm{~m} \\
\text { - Elevasi lantai dermaga } & :+3.2 \mathrm{mLWS} \\
\text { - Daya dukung } & : 1 \mathrm{ton} / \mathrm{m}^{2} \\
\text { - Tahun Pembuatan } & : 1960 \\
\text { - Kolam tambat } & : 3.200 \mathrm{~m}^{2} \\
\text { - Kedalaman kolam } & :-6 \mathrm{~s} / \mathrm{d}-7 \mathrm{Mlws}
\end{array}
$$

\section{Kinerja Fasilitas Pelabuhan}

Kinerja pelayanan general cargo dari 2014-2018 18 ton/gang/jam; pada tahun 2011 terjadi penurunan dikarenakan kinerja pelayanan bagged cargo dari 2014-2018, 20 ton/gang/jam; pada tahun 2017 terjadi penurunan menjadi 18 ton/gang/jam. Kinerja pelayanan petikemas dari 20142018, 9 ton/gang/jam terjadi penurunan juga karena alat bongkar muat tidak bisa berada di atas dermaga karena akses jalan yang sudah rusak dan area pengoperasian yang sangat sempit dan terbatas dan juga tidak terdapat fasilitas terminal dan gudang sementara di area dermaga. Kinerja pelayanan dermaga APO khusus melayani pelayaran perintis selama 2014-2018 berfluktuasi dari $72,16 \%$ sampai $72,86 \%$; pada tahun 2011 terjadi penurunan menjadi 319 ton/m2/kapal dikarenakan keadaan dermaga yang sudah retak dan hancur.

Dengan keadaan yang sekarang ini, dermaga APO dimana beton dermaga buatan tahun 1960 pada zaman pemerintah Hindia Belanda kondisinya yang sudah retak dan akses jalan yang rusak ditambah dengan area yang begitu sempit hanya memiliki luas $346,5 \mathrm{~m}^{2}$, membuat fasilitas 
pendukung seperti forklift tidak dapat beroperasi dengan maksimal dan keberadaan terminal penumpang dan gudang serta ruang trasit (embarkasi/debarkasi) penumpang harus segera dibangun dan dikembangkan.

\section{Results of the SWOT Analysis}

Analisis SWOT berkaitan dengan analisis proses internal dan lingkungan eksternal dengan tujuan mengidentifikasi kekuatan internal agar dapat memanfaatkan peluang eksternal dan menghindari ancaman eksternal, sambil mengatasi kelemahan internal. Metode ini diperkenalkan oleh Albert Humphrey, yang memimpin proyek penelitian di Stanford University pada 1960-an dan 1970-an abad lalu. Metode SWOT digunakan untuk menganalisa Strengths, Weaknesses, Opportunities, and Threats. Hasil dari strategi pengembangan pelayaran perintis dengan menggunakan analisa SWOT dirinci sabagai berikut:

\section{Analisis Faktor Internal (Internal Factors Analysis Summary)}

Analisis terhadap faktor internal pengelolaan pelayaran perintis di pelabuhan Jayapura sebagai upaya untuk penetapan strategi pengembangan pelayaran perintis meliputi 2 komponen yaitu komponen (Strength) dan komponen kelemahan (Weakness).

1. Komponen kekuatan (Strength)

Faktor-faktor yang dianggap sebagai kekuatan pada pengelolaan pelayaran perintis di pelabuhan Jayapura, diantaranya adalah sebagai berikut:

a. Sebagai pusat Ibu Kota provinsi Papua, Pelabuhan Jayapura memiliki peranan penting dalam arus kunjungan kapal, sehingga tentunya pelayaran perintis yang beroperasi dari Indonesia barat sampai Jayapura dan daerah sekitarnya juga memiliki peranan penting; b. Keberadaan Pelayaran Perintis tentu memiliki peranan penting bagi kota Jayapura yang merupakan kawasan strategis dari sudut kepentingan pertahanan dan keamanan Negara, dan kepentingan ekonomi;

c. Pelabuhan Jayapura khususnya Pelayaran Perintis memberikan dampak bagi tatanan sistim jaringan transportasi secara umum di wilayah Provinsi Papua, yang mana berkembang seiring dengan pemberlakuan Otonomi Khusus bagi Papua, dalam transportasi di Provinsi Papua menggambarkan intergrasi dari sub sistim transportasi;

d. Tingkat kepadatan dan kesibukan pelabuhan sebagai pelayaran perintis pelabuhan Jayapura;

e. Pengetahuan pengelola pelabuhan tentang peraturan pengoperasian kapal perintis;

f. Pengetahuan pengelola pelabuhan tentang jenis dan tipe kapal yang sesuai dan diperbolehkan bagi pelayanan perintis;

g. Pengetahuan pengelola tentang jenis muatan kapal.

2. Komponen Kelemahan (Weakness)

Selain faktor kekuatan yang dimiliki, pengelolaan pelayaran perintis sebagai upaya pengembangan fasilitas pelayaran perintis juga terdapat faktorfaktor yang merupakan kelemahan diantaranya adalah sebagai berikut:

a. Ketidaksesuaian antara arus kunjungan kapal dan muatan barang;

b. Sarana dan prasarana tidak menunjang kegiatan pelabuhan sebagai pelayaran perintis;

c. Rute trayek pelayaran perintis di Pelabuhan Jayapura belum dapat melayani dengan maksimal sesuai kebutuhan masyarakat dan daerah;

d. Kurang integrasi antara pelabuhan Jayapura sebagai pelabuhan induk 
ke pengembangan pelabuhan perintis;

e. Kebutuhan alat bantu bongkar muat;

f. Pelayanan bongkar muat barang muatan tidak sesuai;

g. Kurangnya perhatian lembaga instansi/stakeholders yang berwenang terhadap kebutuhan untuk menunjang efektifitas pelayaran perintis;

h. Ketidaksesuaian antara jumlah dan jenis kapal yang masuk dan keluar;

i. Dermaga APO untuk pelayaran perintis memiliki kondisi bangunan yang sudah retak dengan umur bangunan berkisar 58 tahun dan memiliki akses jalan yang rusak ditambah dengan area yang begitu sempit hanya memiliki luas 346,5 $\mathrm{m}^{2}$.

\section{Analisis Faktor Eksternal (External Factors Analysis Summary)}

Analisis eksternal dilakukan terhadap komponen dari luar yaitu Peluang (Opportunities), dan ancaman (Threats) dari rencana pengembangan pengelolaan pelayaran perintis

1. Komponen Peluang (Opportunities) Faktor-faktor yang dianggap sebagai peluang dari pengelolaan pelayaran perintis di pelabuhan Jayapura, diantaranya adalah sebagai berikut:

a. Rencana pemerintah pusat dan daerah untuk mengembangkan pusat kegiatan berbasis potensi sumber daya alam dan kegiatan budi daya unggulan sebagai penggerak utama perekonomian wilayah; sehingga pelabuhan perintis sebagai pendukung pelabuhan Jayapura sangat penting sebagai integrasi transportasi.

b. Rencana pemerintah meningkatkan pelayanan prasarana dan sarana penunjang kegiatan ekonomi karena Kabupaten dan Kota Jayapura, termasuk dalam kawasan strategis nasional.

c. Papua dengan ibukota Jayapura masuk kedalam percepatan dan perluasan pembangunan indonesia (MP3EI).

d. Provinsi Papua memiliki Kawasan berfungsi lindung meliputi: Kawasan hutan lindung, kawasan cagar alam, kawasan suaka margasatwa, kawasan pantai berhutan bakau, kawasan taman nasional, kwasan rawan bencana, dan sebagainya. Kawasan berfungsi budidaya di Provinsi Papua Barat meliputi kawasan hutan produksi, kawasan pertanian, kawasan perikanan, kawasan pertambangan, kawasan industri, kawasan pariwisata.

e. Pengembangan wilayah hinterland.

f. Pengembangan fasilitas pelabuhan seperti terminal penumpang.

2. Komponen Ancaman (Threats)

Selain faktor peluang yang dimiliki, pengelolaan pelayaran perintis sebagai upaya pengembangan fasilitas pelayaran perintis juga terdapat faktor-faktor yang merupakan ancaman diantaranya adalah sebagai berikut:

a. Kepadatan pengunjung dan penumpang selama proses bongkat muat yang menghambat efektifitas pelabuhan;

b. Ketidaksesuaian lama waktu yang dibutuhkan untuk proses bongkar muat;

c. fasilitas pendukung seperti forklift tidak dapat beroperasi dengan maksimal dan keberadaan terminal penumpang dan gudang;

d. penumpukan jumlah kapal yang antri untuk proses bongkar muat dan masuk pelabuhan;

e. Robohnya bangunan pelabuhan akibat kondisi kelebihan muatan massa dibandingkan dengan umur bangunan.

Secara lengkap strategi pada Matriks SWOT ditunjukkan pada tabel IFAS dan EFAS di bawah ini: 
Strategi Pengembangan Pelayaran Perintis Dengan Analisa SWOT Menuju Penguatan Program Tol Laut Dan Indonesia Sebagai Poros Maritim

Willem Thobias Fofid

Tabel 1. Matrik IFAS Pengembangan pengembangan pelayaran perintis pelabuhan Jayapura

\begin{tabular}{|c|c|c|c|c|}
\hline \multirow{2}{*}{ No. } & FAKTOR INTERNAL & BOBOT ITEM & RATING & SKOR \\
\hline & \multicolumn{4}{|l|}{ Kekuatan } \\
\hline 1. & $\begin{array}{l}\text { Sebagai pusat Ibu Kota provinsi Papua, Pelabuhan } \\
\text { Jayapura dan pelayaran perintis peranan penting }\end{array}$ & 0.07 & 4 & 0.28 \\
\hline 2. & $\begin{array}{l}\text { Kota Jayapura yang merupakan kawasan strategis } \\
\text { dari sudut kepentingan pertahanan dan keamanan } \\
\text { Negara, dan kepentingan ekonomi }\end{array}$ & 0.07 & 4 & 0.28 \\
\hline 3. & $\begin{array}{l}\text { Pelayaran Perintis bagian dari intergrasi dari sub } \\
\text { sistim transportasi }\end{array}$ & 0.06 & 4 & 0.24 \\
\hline 4. & Tingkat kepadatan dan kesibukan pelayaran perintis & 0.07 & 4 & 0.21 \\
\hline 5. & $\begin{array}{l}\text { Pengetahuan pengelola pelabuhan tentang peraturan } \\
\text { pengoperasian kapal perintis }\end{array}$ & 0.06 & 3 & 0.18 \\
\hline 6. & $\begin{array}{l}\text { Pengetahuan pengelola pelabuhan tentang jenis dan } \\
\text { tipe kapal yang sesuai dan diperbolehkan bagi } \\
\text { pelayanan perintis }\end{array}$ & 0.07 & 3 & 0.21 \\
\hline 7. & Pengetahuan pengelola tentang jenis muatan kapal & 0.07 & 3 & 0.21 \\
\hline \multicolumn{4}{|c|}{ Total } & 1.61 \\
\hline & \multicolumn{4}{|l|}{ Kelemahan } \\
\hline 1. & $\begin{array}{l}\text { Ketidaksesuaian antara arus kunjungan kapal dan } \\
\text { muatan barang }\end{array}$ & 0.06 & 2 & 0.12 \\
\hline 2. & $\begin{array}{l}\text { Sarana dan prasarana tidak menunjang kegiatan } \\
\text { pelabuhan sebagai pelayaran perintis }\end{array}$ & 0.05 & 1 & 0.05 \\
\hline 3. & $\begin{array}{l}\text { Rute trayek pelayaran perintis di Pelabuhan } \\
\text { Jayapura belum dapat melayani dengan maksimal } \\
\text { sesuai kebutuhan masyarakat dan daerah }\end{array}$ & 0.05 & 2 & 0.10 \\
\hline 4. & $\begin{array}{l}\text { Kurang integrasi antara pelabuhan Jayapura sebagai } \\
\text { pelabuhan induk ke pengembangan pelabuhan } \\
\text { perintis }\end{array}$ & 0.06 & 2 & 0.12 \\
\hline 5. & Kebutuhan alat bantu bongkar muat & 0.07 & 1 & 0.07 \\
\hline 6. & $\begin{array}{l}\text { Pelayanan bongkar muat barang muatan tidak } \\
\text { sesuai }\end{array}$ & 0.05 & 1 & 0.05 \\
\hline 7. & $\begin{array}{l}\text { Kurangnya perhatian lembaga instansi/stakeholders } \\
\text { yang berwenang terhadap kebutuhan untuk } \\
\text { menunjang efektifitas pelayaran perintis }\end{array}$ & 0.05 & 2 & 0.10 \\
\hline 8. & $\begin{array}{l}\text { Ketidaksesuaian antara jumlah dan jenis kapal yang } \\
\text { masuk dan keluar }\end{array}$ & 0.05 & 2 & 0.10 \\
\hline 9. & $\begin{array}{l}\text { Dermaga APO untuk pelayaran perintis memiliki } \\
\text { kondisi bangunan yang sudah retak dengan umur } \\
\text { bangunan berkisar } 58 \text { tahun dan memiliki akses } \\
\text { jalan yang rusak ditambah dengan area yang begitu } \\
\text { sempit hanya memiliki luas } 346,5 \mathrm{~m}^{2}\end{array}$ & 0.07 & 1 & 0.07 \\
\hline & Total & & & 0.78 \\
\hline
\end{tabular}


Tabel 2. Matrik EFAS Pengembangan pengembangan pelayaran perintis pelabuhan Jayapura

\begin{tabular}{|c|c|c|c|c|}
\hline \multirow{2}{*}{ No. } & FAKTOR INTERNAL & BOBOT ITEM & RATING & SKOR \\
\hline & \multicolumn{4}{|l|}{ Peluang } \\
\hline 1. & $\begin{array}{l}\text { Rencana pemerintah pusat dan daerah untuk } \\
\text { mengembangkan pusat kegiatan berbasis potensi } \\
\text { sumber daya alam }\end{array}$ & 0.10 & 4 & 0.4 \\
\hline 2. & $\begin{array}{l}\text { Rencana pemerintah meningkatkan pelayanan } \\
\text { prasarana dan sarana penunjang kegiatan ekonomi }\end{array}$ & 0.10 & 4 & 0.4 \\
\hline 3. & $\begin{array}{l}\text { Papua dengan ibukota Jayapura masuk kedalam } \\
\text { (MP3EI). }\end{array}$ & 0.08 & 4 & 0.32 \\
\hline 4. & $\begin{array}{l}\text { Provinsi Papua memiliki Kawasan berfungsi, } \\
\text { kawasan hutan produksi, kawasan pertanian, } \\
\text { kawasan perikanan, kawasan pertambangan, } \\
\text { kawasan industri, kawasan pariwisata. }\end{array}$ & 0.09 & 4 & 0.36 \\
\hline 5. & Pengembangan wilayah hinterland & 0.08 & 3 & 0.27 \\
\hline \multirow[t]{3}{*}{6.} & $\begin{array}{l}\text { Pengembangan fasilitas pelabuhan seperti terminal } \\
\text { penumpang }\end{array}$ & 0.09 & 3 & 0.27 \\
\hline & Total & & & 2.0 \\
\hline & \multicolumn{4}{|l|}{ Ancaman } \\
\hline 1. & $\begin{array}{l}\text { Kepadatan pengunjung dan penumpang selama } \\
\text { proses bongkat muat yang menghambat efektifitas } \\
\text { pelabuhan }\end{array}$ & 0.09 & 1 & 0.10 \\
\hline 2. & $\begin{array}{l}\text { Ketidaksesuaian lama waktu yang dibutuhkan } \\
\text { untuk proses bongkar muat }\end{array}$ & 0.09 & 1 & 0.09 \\
\hline 3. & $\begin{array}{l}\text { Fasilitas pendukung seperti forklift tidak dapat } \\
\text { beroperasi dengan maksimal dan keberadaan } \\
\text { terminal penumpang dan gudang serta ruang trasit } \\
\text { (embarkasi/debarkasi) }\end{array}$ & 0.10 & 1 & 0.10 \\
\hline 4. & $\begin{array}{l}\text { penumpukan jumlah kapal yang antri untuk proses } \\
\text { bongkar muat dan masuk pelabuhan }\end{array}$ & 0.09 & 1 & 0.09 \\
\hline 5. & $\begin{array}{l}\text { Robohnya bangunan pelabuhan akibat kondisi } \\
\text { kelebihan muatan massa dibandingkan dengan } \\
\text { tuanya bangu } \backslash l \text { lp Op'nan }\end{array}$ & 0.09 & 2 & 0.18 \\
\hline & Total & & & 0.56 \\
\hline
\end{tabular}

Berdasarkan nilai total skor matrik IFAS $(0,83)$ dan EFAS $(1,44)$ dapat dipetakan dalam bentuk diagram analisis SWOT (space matric). Diagram ini dapat mengetahui posisi Strategi kebijakan pengelolaan pelayaran perintis di pelabuhan Jayapura. Dengan diketahuinya posisi strategi berdasarkan analisis matriks space dan penggambarannya dalam garis vektor, maka hasil pemetaan posisi strategi tersebut dapat dilihat pada gambar berikut:

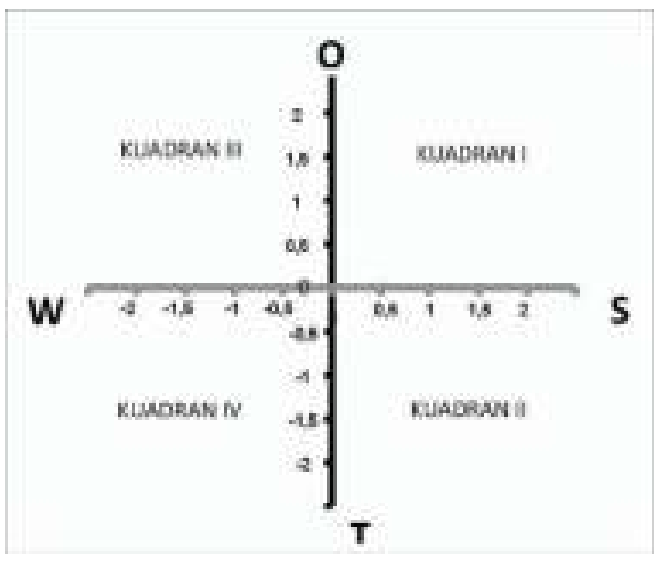

Gambar Diagram Analisis SWOT

Hasil diagram analisis SWOT menunjukkan bahwa strategi yang cocok digunakan dalam analisis kebijakan pengelolaan pelayaran perintis di pelabuhan Jayapura adalah strategi SO (strength- 
opportunity). Strategi SO tersebut yaitu penguatan fungsi pelayaran perintis sebagai pendukung pengembanagn pusat kegiatan ekonomi dan pendukung pemerintah dalam MP3EI, pengembanagn sarana dan prasarana pelabuhan perintis agar dapat menunjang segala aktivitas dan efisiensi pelabuhan, pengembangan wilayah hinterland untuk memaksimalkan fungsi pelayaran perintis yang sibuk dan padat.

\section{PENUTUP}

Aspek-aspek yang menjadi kelemahan dari dermaga APO sebagai Pelayaran Perintis di Pelabuhan Jayapura antara lain terkait masalah ketidaksesuaian antara arus kunjungan kapal dan bongkar muat, masalah prasarana dan sarana di dalam pelabuhan, masalah umur bangunan pelabuhan. Hasil analisis SWOT menunjukan kinerja Pelayaran Perintis pelabuhan Jayapura berada pada kuadan I dengan posisi $(0,83 ; 1,44)$ Strategi yang digunakan Pelayaran Perintis pelabuhan Jayapura guna mengembangkan pelayaran perintis agar lebih efisien sesuai fungsinya adalah adalah strategi SO (strengthopportunity) dengan menggunakan kelebihan yang dimiliki serta potensi yang ada untuk penerapan implementasinya dan mampu menutupi kelemahan-kelemahan yang ada.

\section{DAFTAR PUSTAKA}

Badan Litbang Perhubungan. 2007. Studi Kebutuhan Jaringan Angkutan Laut Perintis Jangka Menengah dalam Upaya Mendorong Pertumbuhan Sektor Lain. Jakarta : Badan LITBANG Perhubungan

Badan Perencanaan Pembangunan Nasional. 2015. Pengembangan Tol laut dalam RPJMN 2015-2019 dan Implementasi 2015. retrieved from https://www.bappenas.go.id/files/Pe ngembangan $\% 20$ Tol $\% 20$ Laut $\% 20 \mathrm{D}$ alam\%20RPJMN\%202015-
2019\%20Dan\%20Implementasi\%20 2015.pdf

Indriastiwi F. 2017. The Requirements of Additional Pioneers Vessel in Area of Banyuwangi. Warta Penelitian Perhubungan. 29 (2): 303-316

Kadarisman M, Yuliantini, Majid SA. 2016. Formulasi Kebijakan Sistem Transportasi Laut”. Jurnal Manajemen Transportasi \& Logistik. 3(2): 161-183

Kementerian Kelautan dan Perikanan. 2017. Maritim Indonesia, Kemewahan Yang Luar Biasa. retrieved from https://kkp.go.id/artikel/2233maritim-indonesia-kemewahanyang-luar-biasa

Peraturan Pemerintah Republik Indonesia Nomor 20 Tahun 2010 Tentang Angkutan Di Perairan

Triatmodjo, B. 2010. Perencanaan Pelabuhan. Yogyakarta : Beta Offset

UNCLOS (United Nations Convention on the Law of the Sea) 1982 Article 46

Wang K A. 2007. Process View of SWOT Analysis, The 51st Annual Meeting of the International Society for the Systems Sciences. Tokyo

Oktarina, Merry. 2012. Competitiveness of Indonesian Officers A Comparative Study with Filipino Officers Under Analytical Hierarcy Process. Kingdom of Netherland : STC Netherland Maritime University

Rangkuti, R.S., Mardiyono, dan Riyanto. 2012. Analisis SWOT Teknik Membedah Kasus Bisnis, Reorientasi Konsep Konsep Perencanaan Strategis Untuk Menghadapi Abad 21. Jakarta : PT. Gramedia 
Sugiyono. 2009. Metode Penelitian Kuantitatif Kualitatif dan $R \& D$. Bandung : CV. Alfabet

Supriyono, Hadi, Capt, Sp.I, M.M, M.Mar. 2010. Comprehensive review to the STCW. Diplomatic Conference, Manila, Philippines

Peraturan Pemerintah No. 20 Tahun 2010 tentang Angkutan di Perairan, sebagaimana telah diubah dengan PP. No. 22 Tahun 2011 tentang Angkutan di Perairan

Peraturan Pemerintah No. 78 Tahun 2014 tentang Percepatan Pembangunan Daerah Tertinggal Yang Berkaitan Dengan Distribusi Pangan Dan Logistik

Peraturan Presiden No. 26 Tahun 2012 Tentang Cetak Biru Pengembangan Sistem Logistik Nasional

Peraturan Presiden No. 71 Tahun 2015 Tentang Penetapan Dan Penyimpanan Barang Kebutuhan Pokok dan Barang Penting

Peraturan Presiden No. 131 Tahun 2015 Tentang Penetapan Daerah Tertinggal Tahun 2015 - 2019

Peraturan Presiden No. 106 Tahun 2015 Tentang Penyelenggaraan Kewajiban Publik Untuk Angkutan Barang di Laut

Peraturan Presiden No. 2 Tahun 2016 Tentang Penyelenggaraan Kegiatan Pelayanan Publik Kapal Perintis Milik Negara

Peraturan Presiden No. 70 Tahun 2017 Tentang Penyelenggaraan Publik Untuk Angkutan Barang dari dan ke Daerah Tertinggal, Terpencil, Terluar dan Perbatasan

Keputusan Presiden No. 6 Tahun 2017 Tentang Penetapan Pulau-Pulau Kecil Terluar
Keputusan Menteri Perhubungan Nomor 70 tahun 1998 tentang Pengawakan Kapal Niaga

Keputusan Bersama Menteri Perhubungan, Menteri Pendidikan Nasional, Menteri Tenaga Kerja dan Transmigrasi Nomor KM. 41 tahun 2003， 5/U/KB/2003. Kep.208$\mathrm{A} / \mathrm{Men} / 2003$ tentang Quality Standard System (QSS)/Sistem Standar Mutu Kepelautan Indonesia

Keputusan Menteri Perhubungan No. PM. 51 Tahun $2015 \quad$ Tentang Penyelenggaraan Pelabuhan Laut

Keputusan Menteri Perhubungan No. PM. 189 Tahun 2015 Tentang Organisasi Tata Kerja Kementerian Perhubungan

Peraturan Menteri Perhubungan No. PM. 4 Tahun $2016 \quad$ Tentang Penyelenggaraan Kewajiban Pelayanan Publik Untuk Angkutan Barang di Laut

Keputusan Menteri Perhubungan No. KP 901 Tahun 2016 Tentang Rencana Induk Pelabuhan Nasional

Peraturan Menteri Perhubungan No. 7 Tahun 2017 Perubahan atas Permenhub No. 10 Tahun 2016 Tentang Tarif Angkutan Barang di Laut Dalam Rangka Pelaksanaan Kewajiban Pelayanan Publik (PSO)

Peraturan Menteri Perdagangan Nomor 29/M-DAG/PER/5/2017 Tahun 2017 Tentang Perdagangan Antar Pulau

Peraturan Menteri Perhubungan No. PM 35 Tahun $2017 \quad$ Tentang Penyelenggaraan Kegiatan Pelayanan Publik Kapal Perintis Milik Negara

Peraturan Menteri Perhubungan No. 49 Tahun $2017 \quad$ Tentang Penyelenggaraan dan Pengusahaan Jasa Pengurusan Transportasi 
Strategi Pengembangan Pelayaran Perintis Dengan Analisa SWOT Menuju Penguatan Program Tol Laut Dan Indonesia Sebagai Poros Maritim

Willem Thobias Fofid

Peraturan Menteri Perhubungan No. 4 Tahun $2018 \quad$ Tentang Penyelenggaraan Kewajiban Pelayanan Publik Untuk Angkutan Barang di Laut

Peraturan Menteri Perhubungan No. 22 Tahun 2018 Tentang Komponen Penghasilan Dan Biaya Yang Diperhitungkan Dalam Kegiatan Subsidi Penyelenggaraan Angkutan Barang di Laut

Peraturan Menteri Perhubungan No. PM. 30 Tahun 2018 Tentang Perubahan Ketiga Atas Peraturan Menteri Perhubungan Nomor PM 182 Tahun 2015 Tentang Tarif Muatan Untuk Kegiatan Subsidi Pengoperasian Kapal Ternak

Peraturan Menteri Perhubungan No. PM. 38 Tahun 2018 Tentang Penetapan Jenis Barang Dari Dan Ke Daerah Tertinggal, Terluar, dan Perbatasan

Surat Direktur Jenderal Perhubungan Laut SK. Jaringan Tarayek AL. 108/7/8/DJPL-15 Tahun 2015

Tentang Jaringan Trayek Pelayaran Tol Laut Tahun Anggaran 2016 Dan Ketentuan-Ketentuan

Pelaksanaannya Tanggal 21 Desember 2015

Keputusan Direktur Jenderal Perhubungan Laut No. AL. 108/3/1/DJPL-2017
Tentang Perubahan Keempat atas Keputusan Dirjen Laut No. AL. 108/1/1/DJPL-17 Tentang Jaringan Trayek Penyelenggaraan Angkutan Barang di Laut Tahun Anggaran 2017

Surat Direktur Jenderal Perhubungan Laut Nomor PR. 101/139/14/DA-2017 Tanggal 3 Oktober 2017 Tentang Penggunaan Ruang Muat Kapal Tol Laut

Surat Direktur Jenderal Perhubungan Laut Nomor UM. 002/84/9/DJPL-17 Tanggal 27 Oktober 2017 Tentang Prosedur Pengaturan Ruang Muat Kapal Tol Laut

Surat Edaran Direktur Jenderal Perhubungan Laut Nomor UM.003/100/11/DJPL-17 Tanggal 28 Desember 2017 Tentang Persyaratan Penyelenggaraan PSO Penumpang Kelas Ekonomi, Angkutan Laut Perintis, PSO Angkutan Barang di Laut (Tol Laut) dan Angkutan Ternak

Keputusan Direktur Jenderal Perhubungan Laut No. AL. 108/5/20/DJPL-17 Tentang Perubahan atas Keputusan Dirjen Laut No. AL. 108/5/11/DJPL-17 Tentang Jaringan Trayek Angkutan Laut Perintis Tahun Anggaran 2018. 